\title{
"Green" Nanozymes: Synthesis, Characterization and Application in Amperometric (Bio)sensors ${ }^{\dagger}$
}

\author{
Galina Z. Gayda 1,*, Olha M. Demkiv ${ }^{1}$, Yanna Gurianov ${ }^{2}$, Roman Ya. Serkiz ${ }^{1}$, \\ Mykhailo V. Gonchar ${ }^{1}$ and Marina Nisnevitch ${ }^{2, *}$ \\ 1 Institute of Cell Biology, National Academy of Sciences of Ukraine, Drahomanov Street 14/16, 79005 Lviv, \\ Ukraine; demkivo@nas.gov.ua (O.M.D.); rserkiz@gmail.com (R.Y.S.); gonchar@cellbiol.lviv.ua (M.V.G.) \\ 2 Department of Chemical Engineering, Ariel University, Kyriat-ha-Mada, Ariel 4070000, Israel; \\ yannag@ariel.ac.il \\ * Correspondence: galina.gayda@nas.gov.ua (G.Z.G.); marinan@ariel.ac.il (M.N.); \\ Tel.: +380-226-2144 (G.Z.G.); +972-3914-3042 (M.N.) \\ + Presented at the 1st International Electronic Conference on Biosensors, 2-17 November 2020; Available \\ online: https://iecb2020.sciforum.net/.
}

Received: date; Accepted: date; Published: date

\begin{abstract}
Nanozymes (NZs) are catalytically active nanomaterials, which have enzyme-like activity, but possess increased stability and greater availability due to simpler preparation technologies. NZs as nanoscale artificial enzymes demonstrate various catalytic specificities as oxidoreductases, such as peroxidase, catalase, laccase and others, as well as hydrolases, proteases, endonucleases, DNAases, NO synthases, etc. A broad variety of NZs exhibits dual- or multienzyme mimetic activity. NZs as stable low-cost mimetics of natural enzymes have a high potential for application in different branches of biotechnology, including scientific investigations, industry and ecology. NZs can be applied in medicine as diagnostic tools and components of therapeutic drugs. Since NZs have high catalytic activity and chemical and biological stability, they are very promising in construction of biosensors and biofuel cells. For these reasons, the search for simple methods of synthesis and characterization of different NZs is a very important and actual problem. The "green" synthesis of Prussian blue analogous as peroxidase-like NZs using oxido-reductases was described in this study. The obtained green-synthesized hexacyanoferrates (gHCF) of transition metals were characterized by structure, size, composition, catalytic properties, electro-mediator activities and substrate specificity. Copper hexacyanoferrate (gCuHCF) was studied in more detail. When immobilized on a graphite electrode (GE), gCuHCF under special conditions of $\mathrm{pH}$ and tension, gave amperometric signals on hydrogen peroxide and can be used as a peroxidase mimetic in oxidase-based biosensors. Under other conditions, gCuHCF/GE reacts to other analytes. We propose, that gHCF of transition metals synthesized via enzymes may become prospect platforms for construction of multifunctional amperometric (bio)sensors.
\end{abstract}

Keywords: Nanozymes; green synthesis; copper hexacyanoferrate; peroxidase mimetic; amperometric (bio)sensor

\section{Introduction}

Artificial enzymes which are effective stable low-cost mimetics of natural enzymes have a great potential for application in industry and medicine. Nanozymes (NZs) are the newest class of functional nanomaterials with enzyme-like activity, that possess increased stability and greater availability due to simpler preparation technologies. To date, over 300 types of NZs were described that include catalysts with different reaction specificities. They are mainly oxidoreductases (peroxidase, haloperoxidase, catalase, laccase, different oxidases, superoxide dismutase, 
monoxygenase), proteases, as well as hydrolases, endonucleases, DNA-ases, NO synthases, etc. A large variety of NZs simultaneously exhibit multienzyme mimetic activity [1-4]. Thus, "nanozymology", as a new field of science connecting nanotechnology and enzymology, has great potential for further development and for many practical future applications [4-7]. The search for novel effective NZs, the development of simple methods for their synthesis and characterization, as well as the selection of novel branches for their application are currently booming problems in different fields of biotechnology.

Peroxidase (PO)-mimetics are the most investigated NZs [2-4]. One of the most effective PO-like NZ is Prussian blue (PB). PB or iron(III) hexacyanoferrate(II) is a member of a well-documented family of synthetic coordination compounds with an extensive 300-year history. It was produced commercially in the past and used as a pigment for paints, lacquers, printing inks and laundry dyes [8,9]. PB and its analogues (PBAs) are easy to synthesize, cheap, environmentally friendly and have potential applications in a large variety of fields, including basic research and industrial purposes [3,10-12], and particularly in medicine [5,7,13-15]. Despite their multifunctionality, PBAs have complicated compositions, which are largely dependent on the synthesis methods and storage conditions [3,16]. Insoluble $\mathrm{PB}$ can be described by the formula $\mathrm{Fe}_{4}\left[\mathrm{Fe}(\mathrm{CN})_{6}\right]_{3}$, and $\mathrm{KFe}\left[\mathrm{Fe}(\mathrm{CN})_{6}\right]$ corresponds to a colloidal solution of PB [8-10]. The general formula of hexacyanoferrate (HCF) is $\mathrm{M}_{\mathrm{k}}\left[\mathrm{Fe}(\mathrm{CN})_{6}\right] \times \mathrm{H}_{2} \mathrm{O}$, where $\mathrm{M}$ is a transition metal.

In two last decades, PBAs have gained extensive worldwide attention. Metal-to-metal charge transfer between the two transition metal ions in the complex-compound salt as well as the nanosize of HCF particles are the reasons for PBAs' redox activity and super-magnetic properties. Due to these remarkable properties, PBAs are widely applied in optics, molecular magnets, electrochemistry [3,6,7,9-11] and in bioreactors for detoxification of the environment from dangerous chemicals [12].

Due to their capability of inserting various ions as counter-ions during the redox process, PB and PBAs gained increasing interest as electrode materials for energy storage in fuel cells [9-10,17]. PB and PBAs are successfully used in optical biosensors as a result of their PO-like properties [1719]. The first communications concerning electrochemical reduction of $\mathrm{H}_{2} \mathrm{O}_{2}$ on $\mathrm{PB}$-modified glassy carbon electrode were done by Itaya and colleagues [20]. Numerous reports on the use of PB as an artificial PO in amperometric biosensors were published by Karyakin and colleagues over the last 25 years [17,21-24]. In 2000, this group named PB an "artificial PO" [21]. At the same time, a large number of other scientific groups, especially from China, worked hard on this problem [1-5,9-15].

PBAs are usually obtained via various techniques, including chemical [9-11,17] and alternative biological methods [25,26]. The biosynthesis of nanoparticles (NPs) using plants, microorganisms and their metabolites, including polysaccharides, proteins, polypeptides and other compounds, is called "green" synthesis. The advantages of green synthesis methods are the use of nontoxic reactants derived from living organisms, including plants, algae, microorganisms, mammalian cells and their metabolites [27,28]. Purified enzymes [29-31] were also shown to be capable of reducing metal ions for obtaining metallic NPs.

Green synthesis of various PBAs with plant extracts as biosurfactants was described, much of the data were reported by Shanker and colleagues $[25,26]$. The green-synthesized nanocomposites were used for sunlight-mediated photocatalytic degradation of toxic chemicals in water solutions, including phenolic compounds and organic dyes [32]. These PBAs can therefore be prospective for detoxification of industrial wastes.

Application of PBA obtained with green synthesis for construction of amperometric biosensors is not well documented. The main benefits of green-synthesized nanomaterials are the low energy cost of their synthesis, lack of toxic chemicals, simplicity of procedure, high adaptability of the synthesized NPs and the presence of functional groups on their surface. These functional groups can be used without any additional activation and functionalization of the NPs surface for immobilization of bioorganic molecules, including enzymes, for biosensor construction [28]. If green NPs have additional enzyme-like properties, they may play a dual role in biosensors, serving at the same time as carriers of biorecognition elements and as enzyme mimetics. 
In the present study we used purified yeast enzyme flavocytochrome $b_{2}$ ( $\mathrm{Fc} b_{2}$; L-lactate: ferricytochrome c oxidoreductase, EC 1.1.2.3) for reduction of potassium ferricyanide for green synthesis of PBAs. In our earlier works, we described the development of analytical methods based on enzyme-catalyzed formation of PB: to visualize the activity of $\mathrm{Fc} b_{2}$ in polyacrylamide gel [33] and to quantify L-lactate concentrations in solutions [34]. In the current manuscript we report green synthesis of PBAs or hexacyanoferrates (gPBAs or $\mathrm{gHCFs}$ ) of several transition metals, their characterization as well as demonstration of the potential application of gHCFs as amperometric sensors. It is concluded that gHCF of transition metals synthesized via enzymes may be prospective platforms for construction of oxidase-based amperometric biosensors.

\section{Materials and Methods}

\subsection{Reagents}

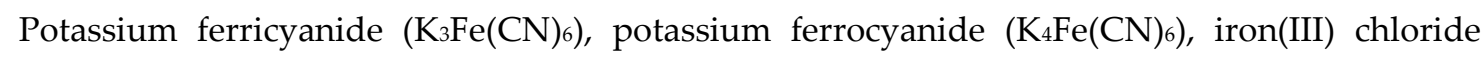
$\left(\mathrm{FeCl}_{3} \times 4 \mathrm{H}_{2} \mathrm{O}\right)$, copper(II) sulfate $\left(\mathrm{CuSO}_{4}\right)$, cobalt(II) chloride $\left(\mathrm{CoCl}_{2} \times 6 \mathrm{H}_{2} \mathrm{O}\right)$, zinc(II) sulfate $\left(\mathrm{ZnSO}_{4}\right)$, manganese(II) chloride $\left(\mathrm{MnCl}_{2} \times 4 \mathrm{H}_{2} \mathrm{O}\right)$, cadmium(II) chloride $\left(\mathrm{CdCl}_{2}\right)$, neodymium(III) chloride $\left(\mathrm{NdCl}_{3}\right), 2,2$ '-azinobis (3-ethylbenzothiazoline-6-sulfonate) diammonium salt (ABTS), hydrogen peroxide $\left(\mathrm{H}_{2} \mathrm{O}_{2}, 30 \%\right)$, sodium ethylenediaminetetraacetate (EDTA), sodium L-lactate, and all other reagents and solvents used in this work were purchased from Sigma-Aldrich (Steinheim, Germany). All reagents were analytical grade and were used without further purification. All solutions were prepared with ultra-pure water prepared with Milli-Q ${ }^{\circledR}$ IQ 7000 Water Purification system (Merck KGaA, Darmstadt, Germany). Nafion (5\% solution in 90\% low-chain aliphatic alcohols) was obtained from Sigma-Aldrich (Steinheim, Germany).

\subsection{Enzymes}

Flavocytochrome $b_{2}\left(\mathrm{Fc}_{2}\right)$ was isolated from the yeast Ogataea (Hansenula) polymorpha 356 and purified as described earlier [33,34]. Fc $b_{2}\left(20 \mathrm{U} \cdot \mathrm{mg}^{-1}\right)$ was stored at $-10{ }^{\circ} \mathrm{C}$ in a suspension of $70 \%$ ammonium sulfate, prepared with $50 \mathrm{mM}$ phosphate buffer, $\mathrm{pH}$ 7.5, containing $1 \mathrm{mM}$ EDTA and 0.1 $\mathrm{mM}$ DTT. To prepare a fresh solution, the enzyme was precipitated from the suspension by centrifugation (10,000 rpm, $10 \mathrm{~min}, 4^{\circ} \mathrm{C}$ ) and dissolved in $50 \mathrm{mM}$ phosphate buffer, $\mathrm{pH} 7.5$, up to 50 $\mathrm{U} \cdot \mathrm{mL}^{-1}$. Assay of $\mathrm{Fc} b_{2}$ activity in solution and visualization in PAAG were performed as described earlier [33]. One unit of the enzyme activity is defined as the amount of enzyme which oxidizes 1 $\mu \mathrm{mol}$ of L-lactate in $1 \mathrm{~min}$ under standard assay conditions $\left(20^{\circ} \mathrm{C} ; 30 \mathrm{mM}\right.$ phosphate buffer, $\mathrm{pH} 7.5$; 0.33 M L-lactate; $0.83 \mathrm{mM} \mathrm{K}_{3}\left(\mathrm{Fe}(\mathrm{CN})_{6} ; 1 \mathrm{mM}\right.$ EDTA).

A commercial lyophilized horseradish peroxidase (PO or HRP, EC 1.11.1.7) from Armoracia rusticana (Aster, Lviv, Ukraine) with $600 \mathrm{U} \cdot \mathrm{mg}^{-1}$ activity was dissolved in $20 \mathrm{mM}$ phosphate buffer, pH 6.0, up to $400 \mathrm{U} \cdot \mathrm{mL}^{-1}$.

A commercial lyophilized glucose oxidase (GO, EC 1.1.3.4) from Asperigillus niger (Sigma, St. Louis, MO) with an activity of $100 \mathrm{U} \cdot \mathrm{mg}^{-1}$ was dissolved in $20 \mathrm{mM}$ phosphate buffer, $\mathrm{pH}$ 6.0, up to $100 \mathrm{U} \cdot \mathrm{mL}^{-1}$. GO activity was assayed in a reaction mixture containing $0.16 \mathrm{mM}$ o-dianisidine, $1.61 \%$ (w/v) glucose, and $2 \mathrm{U} / \mathrm{mL}$ of $\mathrm{PO}$ in $50 \mathrm{mM}$ sodium acetate buffer, $\mathrm{pH}$ 5.0, as described earlier [35].

\subsection{Synthesis of Hexacyanoferrates}

Synthesis of gHCFs was carried out according to the scheme presented in Figure 1. A reaction mixture containing $6 \mathrm{mM} \mathrm{K} 3\left[\mathrm{Fe}(\mathrm{CN})_{6}\right], 20 \mathrm{mM}$ sodium lactate, $0.03-0.15 \mathrm{U} / \mathrm{mL}$ Fc $b_{2}$ in $50 \mathrm{mM}$ phosphate buffer, $\mathrm{pH} 8.0$, was prepared and incubated at $37 \mathrm{C}$ for 10-30 min up to discoloration of the yellow solution. Formation of gPBA (or gHCF) was initiated by addition of salt to a final concentration of $10-100 \mathrm{mM}$. 


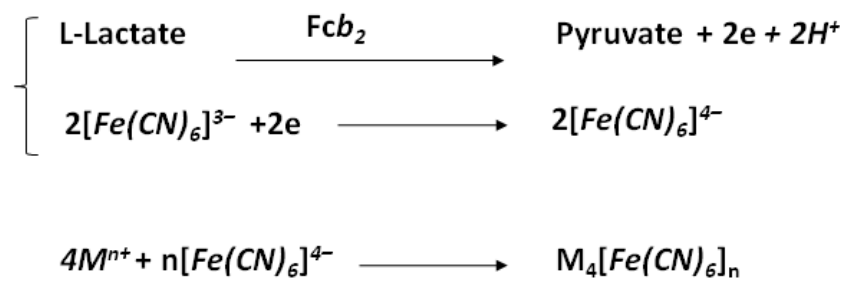

Figure 1. Scheme of gHCF synthesis using Fcb2 due to enzymatic (1) and chemical (2) reactions; M transition metal.

To obtain chemically synthesized HCFs (chHCFs), a solution of $6 \mathrm{mM} \mathrm{K}_{3}\left[\mathrm{Fe}(\mathrm{CN})_{6}\right]$ and $60 \mathrm{mM}$ transition metal salt in $50 \mathrm{mM}$ phosphate buffer, $\mathrm{pH}$ 8.0, was mixed with $\mathrm{H}_{2} \mathrm{O}_{2}$ added dropwise up to $100 \mathrm{mM}$. After $0.5-10 \mathrm{~min}$ incubation, the resulting mixture was fractionated by centrifugation at 13,000 rpm for $1 \mathrm{~min}$ and the precipitate was re-suspended in water. The centrifugation-redispersion procedure was repeated 2-4 times. The obtained HCFs were re-suspended in water and kept at -20 ${ }^{\circ} \mathrm{C}$ until used.

\subsection{Assay of Enzyme-Like Activities of the Synthesized HCFs}

$10 \mu \mathrm{L}$ of the aqueous suspension of HCF was incubated in a $1 \mathrm{~mL}$ quartz cuvette with $1 \mathrm{mM}$ ABTS in $50 \mathrm{mM} \mathrm{NaOAc}$ buffer, $\mathrm{pH} 4.5$ (as a chromogenic substrate for oxidase), and with the same substrate in the presence of $12 \mathrm{mM} \mathrm{H}_{2} \mathrm{O}_{2}$ (as a substrate for PO). Addition of HCF to the correspondent substrate (ABTS - for oxidase, ABTS with $\mathrm{H}_{2} \mathrm{O}_{2}$ - for PO) stimulates the development of a green color over time, as in an enzymatic reaction. The enzyme-mimetic activity can be assessed qualitatively with the naked eye. It can also be measured quantitatively with spectrophotometer. The speed of appearance of a green color was monitored over time at $420 \mathrm{~nm}$, thus enabling calculation of the enzyme-like activity [17].

\subsection{Characterization of the Synthesized HCFs}

\subsubsection{Optical Properties}

The optical properties of the synthesized gHCFs and chHCFs, their concentrations and $\mathrm{Fc} b_{2}$ activity, were characterized using a Shimadzu UV1650 PC spectrophotometer (Kyoto, Japan).

\subsubsection{Scanning Electron Microscopy (SEM)}

Morphological analyses of the samples were performed using a SEM-microanalyzer REMMA102-02 (Sumy, Ukraine). The samples of different dilutions $(2 \mu \mathrm{L})$ were dropped on the surface of a silicon wafer and dried at room temperature. The distance from the last lens of the microscope to the sample (WD) ranged from $17.1 \mathrm{~mm}$ to $21.7 \mathrm{~mm}$. The accelerator voltage was in the range of 20 to 40 $\mathrm{eV}$.

\subsubsection{FTIR Analysis}

The infrared spectra were prepared using the $\mathrm{KBr}$ pellet technique, by thoroughly mixing $3 \mu \mathrm{L}$ of a particle suspension with $0.2 \mathrm{~g}$ of $\mathrm{KBr}$ and pressing at 5 tonf using a hydraulic press (Carver ${ }^{\circledR}$ Inc., Wabash, USA). The samples were dried in a desiccator overnight and analyzed by the SpectrumTM One FTIR Spectrometer (Perkin Elmer, Waltham, MA, USA) at room temperature in the $4000-400 \mathrm{~cm}^{-1}$ range at an operation number of 20 scans, a resolution of $4.0 \mathrm{~cm}^{-1}$ and a scanning interval of $1 \mathrm{~cm}^{-1}$.

\subsubsection{Particle Counter Analysis}

Particle concentration was measured using a particle counter (Spectrex Corp., Redwood, CA) in round-shaped $150 \mathrm{~mL}$ transparent glass bottle with a wall thickness of $2 \mathrm{~mm}$. $10 \mu \mathrm{L}$ of sample were 
added into the bottle with $99 \mathrm{~mL}$ of water (HPLC grade, Bio-Lab Ltd., Jerusalem, Israel) under continuous stirring. Particle counting was operated with a laser diode at a wavelength of $650 \mathrm{~nm}$.

\subsubsection{Dynamic Light Scattering (DLS) Analysis and Zeta-Potential Measurements}

DLS analysis and zeta-potential measurements were performed using a Litesizer 500 type BM10 instrument (Anton Paar $\mathrm{GmbH}, \mathrm{Graz}$, Austria) at $25{ }^{\circ} \mathrm{C}$. For measurement of hydrodynamic diameters, the samples were diluted 1:150, 1:300 and 1:600 with HPLC grade water, placed into a semi-micro quartz cell and analyzed using laser at a wavelength of $660 \mathrm{~nm}$ and a side scatter of $90^{\circ}$. Zeta-potential was measured in diluted colloidal solutions at particle concentration of $1.33 \times 10^{4}$, which was determined as described in Section 2.5.4. The solutions were injected into the omega-shaped cuvette and analyzed at an operating voltage of $200 \mathrm{~V}$.

\subsection{Sensor Evaluation}

\subsubsection{Apparatus and Measurements}

The amperometric sensors were evaluated using constant-potential amperometry in a threeelectrode configuration with an $\mathrm{Ag} / \mathrm{AgCl} / \mathrm{KCl}(3 \mathrm{M})$ reference electrode, a Pt-wire counter electrode and a working graphite electrode. Graphite rods (type RW001, $3.05 \mathrm{~mm}$ diameter) from Ringsdorff Werke (Bonn, Germany) were sealed in glass tubes using epoxy glue for disk electrodes formation. Before sensor preparation, the graphite electrode (GE) was polished on an emery paper and on a polishing cloth using decreasing sizes of alumina paste (Leco, Germany). The polished electrodes were rinsed with water in an ultrasonic bath.

Amperometric measurements were carried out using a potentiostat CHI 1200A (IJ Cambria Scientific, Burry Port, UK) connected to a personal computer and performed in a batch mode under continuous stirring in an electrochemical cell with a $20 \mathrm{~mL}$ volume at $25^{\circ} \mathrm{C}$.

All experiments have been carried out in triplicate trials. Analytical characteristics of the proposed electrodes were statistically processed using the OriginPro 8.5 software. Error bars represent the standard error derived from three independent measurements. Calculation of the apparent Michaelis-Menten constants $\left(K_{M^{a p p}}\right)$ was performed automatically by this program according to the Lineweaver-Burk equation.

\subsubsection{Immobilization of HCFs and the Enzyme onto Electrodes}

In order to construct the enzyme-based electrode, the GE was modified by dropping $5 \mu \mathrm{L}$ gHCF or chHCF. For construction of the PO-based electrode, $5 \mu \mathrm{L}$ enzyme solution was dropped onto the surfaces of bulk GEs and gHCF/GEs. After drying for $10 \mathrm{~min}$ at room temperature, the layer of gHCF or enzyme on the electrodes was covered with Nafion. The modified electrodes were rinsed with corresponding buffers and kept in these buffers with $0.1 \mathrm{mM}$ EDTA at $4{ }^{\circ} \mathrm{C}$ until used. The electrodes were washed with corresponding buffer solutions before and after each measurement.

$3 \mu \mathrm{L}$ of GO solution (with activity $100 \mathrm{U} \cdot \mathrm{mL}^{-1}$ ) were mixed with $3 \mu \mathrm{L}$ of gCuHCF suspension and dropped on the surface of GE. Dried composite was covered by a Nafion membrane. The coated bioelectrodes were rinsed with water and stored in PB before using.

\section{Results}

\subsection{Green Synthesis of PBA}

The purified microbial enzyme Fcb2 from the yeast strain O. polymorpha 356 was used for the green synthesis of gHCFs. The advantages of this enzyme are its stability and non-selectivity for electron acceptors [33,34]. The scheme in Figure 1 presents the principle of PB and its analogues obtained via Fcb2. 
According to the scheme presented in Figure 1, several gHCFs were obtained from the corresponding salts $\left(\mathrm{Fe}, \mathrm{Cu}, \mathrm{Mn}, \mathrm{Zn}, \mathrm{Cd}\right.$, etc.) and $\mathrm{K}_{4} \mathrm{Fe}(\mathrm{CN})_{6}$, a product of $\mathrm{K}_{3} \mathrm{Fe}(\mathrm{CN})_{6}$ reduction by lactate in the presence of enzyme.

\section{2. gHCFs as Artificial Peroxidases}

\subsubsection{Development and Characterization of gHCFs-Modified Electrodes}

According to the research literature, chemically synthesized HCFs (chHCFs) of Fe (III), Mn (II) and $\mathrm{Cu}$ (II) demonstrate significant PO-like activity in solution and on electrodes [9,10,17,21-24]. Our first task was to screen the obtained gPBAs for their sensitivity to $\mathrm{H}_{2} \mathrm{O}_{2}$ on amperometric GEs and to select the best compounds as PO-mimetics. For this purpose, the optimal conditions for the amperometric experiments were investigated. The amperometric characteristics of the control GE (not modified with gHCF) as a chemosensor for $\mathrm{H}_{2} \mathrm{O}_{2}$ were tested using cyclic voltammetry (CV) analysis. Selection of the optimal $\mathrm{pH}$, working potential and scan rate was carried out according to the $\mathrm{CV}$ results (data not shown).

Under the chosen conditions (50 mM NaOAc buffer, $\mathrm{pH} 4.5$ and $-50 \mathrm{mV}$ as the working potential), numerous electrodes, modified with the synthesized $\mathrm{gHCFs}$, were screened for their ability to decompose hydrogen peroxide. A low working potential is necessity in order to avoid the effect of potential interfering substances on the electrode's response in the presence of oxygen. This requirement will be relevant for the construction of biosensors and their exploitation for analysis of real samples (food products, biological liquids and others). The electrocatalytic activities of the synthesized gPBAs, immobilized on the surface of GEs were tested by CV and chronoamperometry, as described in 2.6.1. The amperometric responses of different gPBA/GEs to the added $\mathrm{H}_{2} \mathrm{O}_{2}$ (up to a final concentration of $1 \mathrm{mM}$ ) were compared. Following the chronoamperograms, calibration curves were plotted for $\mathrm{H}_{2} \mathrm{O}_{2}$ determination by the developed electrodes. The linear ranges and sensitivities of the electrodes modified with gHCF were calculated. The analytical characteristics of the synthesized gHCF/GEs, as deduced from the graphs, are summarized in Table 1. gCuHCF/GE and the $\mathrm{gFeHCF} / \mathrm{GE}$ were found to be the most effective $\mathrm{gHCFs}$, this conclusion is based on sensitivity values.

Table 1. Comparative analytical characteristics of gHCF as a PO-mimetic on GEs.

\begin{tabular}{|c|c|c|c|c|}
\hline Sensitive Film & $K_{M^{a p p}}, \mathrm{mM}$ & ${ }^{*} I_{\max }, \mu \mathrm{A}$ & Linear Range, up to, $\mathrm{mM}$ & Sensitivity, $\mathrm{A} \mathrm{M}^{-1} \mathrm{~m}^{-2}$ \\
\hline $\mathrm{gCuHCF}$ & $31.0 \pm 4.4$ & $138.0 \pm 8.5$ & 0.8 & 1620 \\
\hline gPB & $8.0 \pm 1.1$ & $27.8 \pm 1.0$ & 0.4 & 1090 \\
\hline $\mathrm{PO}$ & $4.9 \pm 1.1$ & $5.0 \pm 0.2$ & 0.4 & 352 \\
\hline chCuHCF & $20.0 \pm 3.5$ & $6.5 \pm 0.4$ & 0.8 & 110 \\
\hline gMnHCF & $92.3 \pm 15.2$ & $21.1 \pm 2.1$ & 0.8 & 98 \\
\hline $\mathrm{gCoHCF}$ & $26.1 \pm 2.9$ & $5.5 \pm 0.2$ & 3.5 & 29 \\
\hline $\mathrm{gZnHCF}$ & $25.5 \pm 2.2$ & $4.0 \pm 0.2$ & 6.5 & 22 \\
\hline $\mathrm{gNdHCF}$ & $21.3 \pm 1.7$ & $3.1 \pm 0.1$ & 6.5 & 16 \\
\hline $\mathrm{gCdHCF}$ & $40.0 \pm 5.4$ & 2. $6 \pm 0.2$ & 1.5 & 15 \\
\hline
\end{tabular}

* measured for the electrode area $7.30 \mathrm{~mm}^{2}$.

\subsubsection{Characterization of the Most Effective Electrodes}

The $\mathrm{gCuHCF} / \mathrm{GE}$ and the $\mathrm{gFeHCF} / \mathrm{GE}$ with the highest PO-like activity were studied in detail. The results of these investigations are illustrated in Figure 2. The gCuHCF/GE and the gFeHCF/GE demonstrated the highest PO-like activities compared with other gHCFs as well as with native PO (Table 1, Figure 2) and chemically synthesized chCuHCF (Table 1). The highest current response (Imax) on the tested analyte at substrate saturation of the $\mathrm{gCuHCF} / \mathrm{GE}$ is 5 -fold higher and the sensitivity is 29-fold higher than that of the PO/GE (Table 1). It is worth mentioning that gCuHCF has PO-like ability but lacks oxidase-like properties (data not shown). This conclusion was reached from the 
results of colorimetric tests using ABTS in the presence of $\mathrm{H}_{2} \mathrm{O}_{2}$ as a substrate for $\mathrm{PO}$, and with ABTS only as a substrate for oxidase (see 2.4). The gCuHCF specificity to $\mathrm{H}_{2} \mathrm{O}_{2}$ is the important valuable characteristic for applying it as a selective PO-mimetic element in biosensors.

The CV analyses were performed in order to characterize gCuHCF and gFeHCF. Modification of GEs with these gHCFs improved the efficiency of electron transfer due to an increase in the electrochemically accessible electrode surface area. The enhancement of signals of the electrodes modified with other gHCFs was insignificant (data not shown). Results presented in Figure 2 and Table 1 support that the $\mathrm{gCuHCF} / \mathrm{GE}$ was the most effective PO-mimetic. It was therefore studied more particularly.

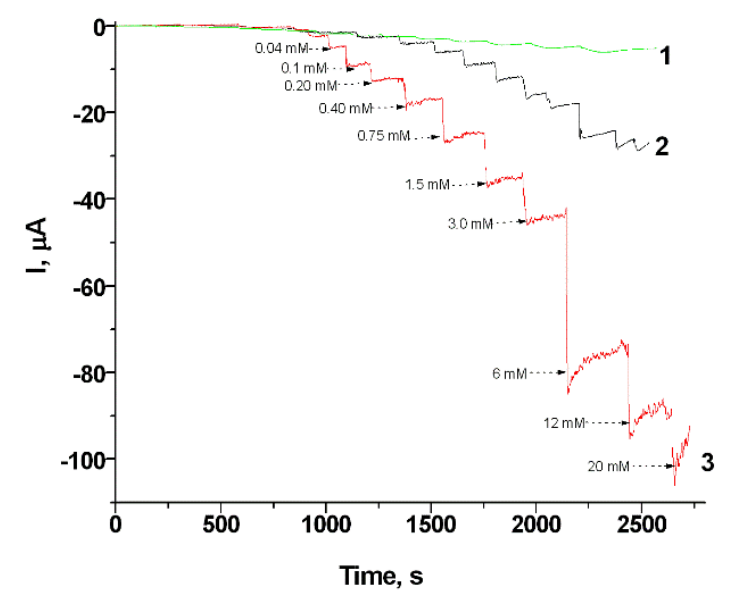

(a)

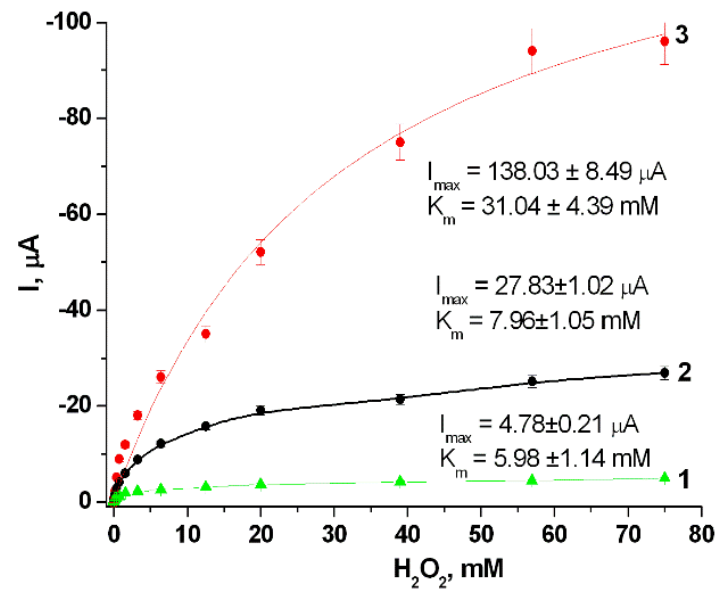

(b)

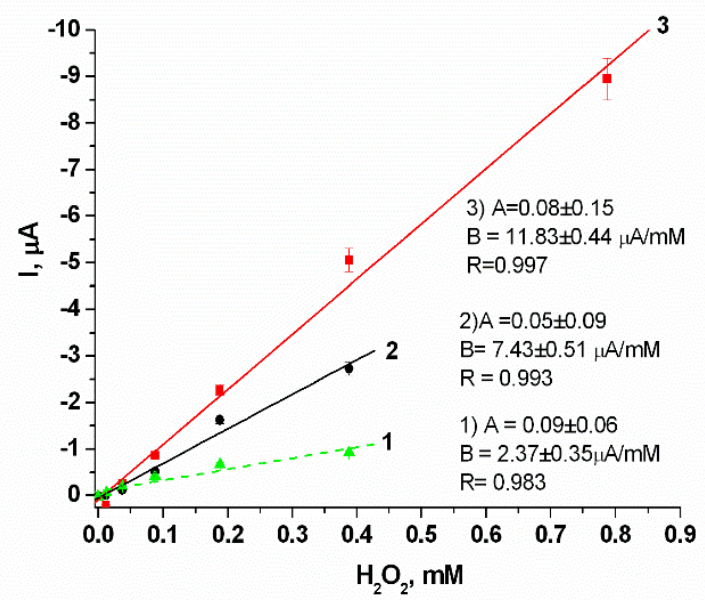

(c)

Figure 2. Amperometric characteristics of the modified electrodes: chronoamperograms (a), dependence of the response on increasing concentrations of $\mathrm{H}_{2} \mathrm{O}_{2}$ (b) and calibration graphs (c) for PO/GE (1), gFeHCF/GE (2) and gCuHCF/GE (3). Conditions: working potential $-50 \mathrm{mV}$ vs. Ag/AgCl (reference electrode), $50 \mathrm{mM} \mathrm{NaOAc}$ buffer, $\mathrm{pH} 4.5$ at $23^{\circ} \mathrm{C}$.

\subsubsection{Application of gCuHCF as a PO-Mimetic in Amperometric (Bio)sensors}

Analysis of the commercial disinfectant Famidez-Sanosil was carried out in order to demonstrate the applicability of gCuHCF as a chemosensor for $\mathrm{H}_{2} \mathrm{O}_{2}$ detection (Figure 3). Sanosil is a versatile simple water disinfectant that can be used for effective biological control, whether for drinking water or in air-conditioning plants, in the pharmaceutical industry or on livestock farms. The manufacturer (Dezomark, Ukraine) claims that the $\mathrm{H}_{2} \mathrm{O}_{2}$ concentration in the product is $2 \%$, which corresponds to 
approximately $600 \mathrm{mM}$. SAT-approach was used to avoid undesirable effects of additives in the tested solution on the analysis result.

Graphical SAT is a type of quantitative analysis often used in analytical chemistry when a standard is added directly to the aliquots of the analyzed sample. Estimation of $\mathrm{H}_{2} \mathrm{O}_{2}$ in the initial sample was performed using the equation $\mathrm{C}=\mathrm{AN} / \mathrm{B}$ where $\mathrm{A}$ and $\mathrm{B}$ are parameters of a linear regression and $\mathrm{N}$ is a dilution factor. The average $\mathrm{H}_{2} \mathrm{O}_{2}$ concentration determined from the data in Figure 3 was $548 \mathrm{mM}$. This result is well-correlated with the manufacturer's data $(600 \mathrm{mM})$ with an error less than $10 \%$.

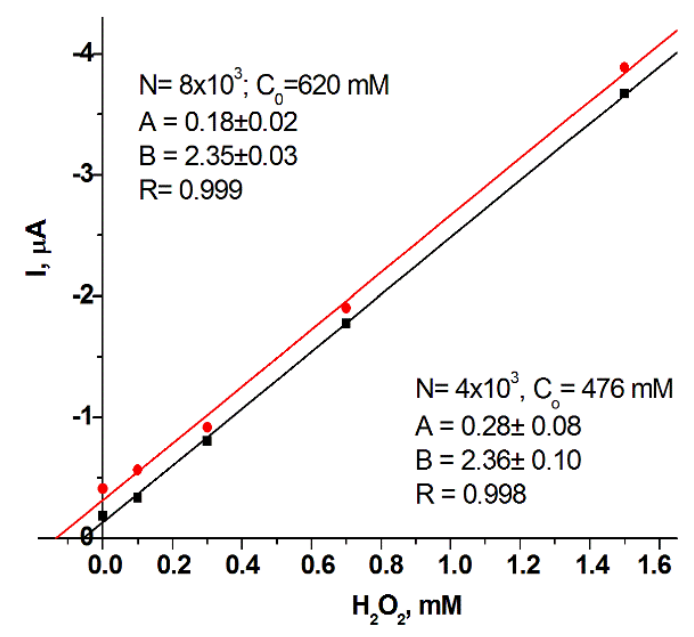

Figure 3. Analysis of a real sample of disinfectant using gCuHCF/GE with the SAT method. Red and black lines correspond to analytes diluted 8,000 and 4,000 times, respectively. $\mathrm{H}_{2} \mathrm{O}_{2}$ aliquots were added to the diluted sample up to final concentrations of $0.1,0.3,0.7$ and $1.5 \mathrm{mM}$. Conditions: working potential $-50 \mathrm{mV}$ vs. $\mathrm{Ag} / \mathrm{AgCl}$ (reference electrode), $50 \mathrm{mM} \mathrm{NaOAc}$ buffer, $\mathrm{pH} 4.5$ at $23^{\circ} \mathrm{C}$.

We performed preliminary experiments on construction of amperometric mono-enzyme biosensor with gCuHCF as the PO-mimetic based on the commercial glucose oxidase (GO) model (Figure 4). Under the tested conditions, the control gCuHCF/GE did not have any amperometric output on glucose. Figure 4 presents the amperometric characteristics of the constructed $\mathrm{GO} / \mathrm{gCuHCF} / \mathrm{GE}$ biosensor: $I_{\max }=1.15 \pm 0.15 \mu \mathrm{A} ; K_{\mathrm{M}^{a p p}}=1.80 \pm 0.47 \mathrm{mM}$; sensitivity $=75.6 \mathrm{~A} \cdot \mathrm{M}^{-1} \cdot \mathrm{m}^{-2}$.

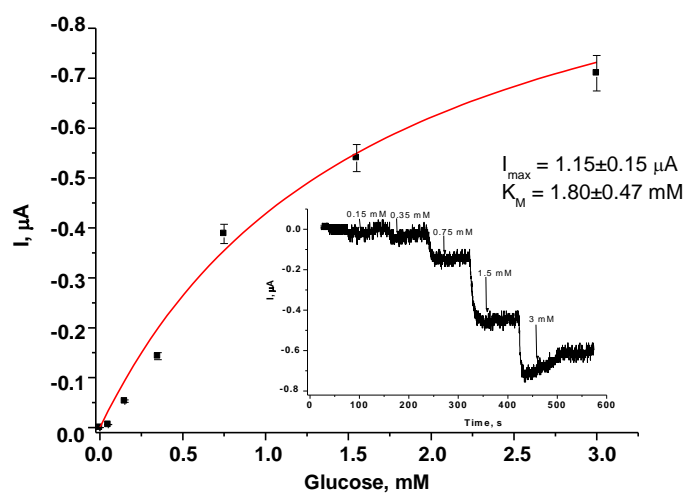

(a)

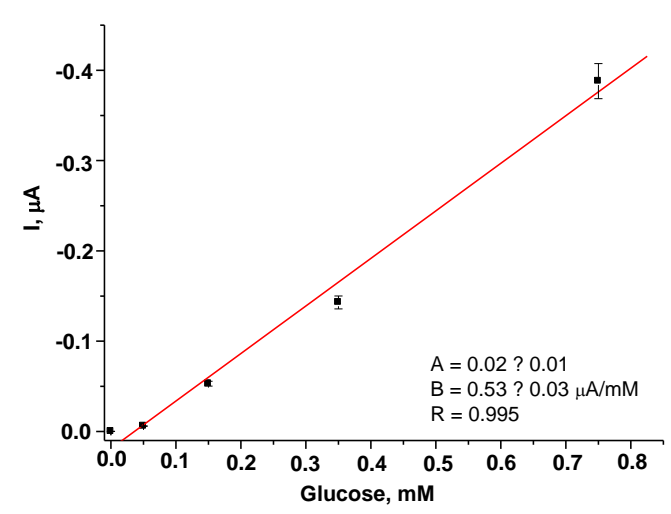

(b)

Figure 4. Characteristics of GO/gCuHCF-GE: (a)-dependence of the amperometric response on increasing concentrations of glucose and chronoamperogram (inset); (b)-calibration graph for glucose determination. Conditions: working potential $-50 \mathrm{mV}$ vs. $\mathrm{Ag} / \mathrm{AgCl}$ (reference electrode), 50 mM K-Na phosphate buffer, $\mathrm{pH} 6.0$ at $23^{\circ} \mathrm{C}$. 


\subsection{Study of Structure, Morphology and Size of the gCuHCF Composite}

The size, morphology and composition of any materials, especially of NPs, are considered as their basic parameters. A number of non-invasive label-free methods were developed for characterization of different materials, namely SEM, transmission electron microscopy (TEM), dynamic light scattering (DLS), Fourier transform infrared spectroscopy (FTIR), Raman spectroscopy, atomic force microscopy (AFM) and other approaches. FTIR spectroscopy enables rapid acquisition of a biochemical fingerprint of the sample under investigation and yields data on its main biomolecule content. DLS allows rapid determination of diffusion coefficients and provides information on relaxation time distribution for the macromolecular components of complex systems and their hydrodynamic diameters. SEM produces images of a sample by scanning the surface with a focused beam of electrons and affords information on the surface topography and composition of the sample. The diversity and ambiguity of green-synthesized materials are the reason why it is necessary to use multiple techniques for their valid characterization.

In our study, the synthesized catalytically active organic-inorganic composite gCuHCF was examined using FT-IR, DLS and SEM. The FTIR spectrum of the sample is presented in Figure 5a. The spectrum proves the presence of the following groups: $\mathrm{O}-\mathrm{H}, \mathrm{N}-\mathrm{H}, \mathrm{C} \equiv \mathrm{N}, \mathrm{C}-\mathrm{H}, \mathrm{C}-\mathrm{O}, \mathrm{C}-\mathrm{N}, \mathrm{Fe}-\mathrm{C} \equiv \mathrm{N}$ and $\mathrm{H}_{2} \mathrm{O}-\mathrm{Cu}-\mathrm{CN}$. Hydroxyl groups were identified by the bands at 3456 and $3050 \mathrm{~cm}^{-1}$ related to O$\mathrm{H}$ stretching vibrations and $1398 \mathrm{~cm}^{-1}$ which corresponds to $\mathrm{O}-\mathrm{H}$ bending [49]. Amine groups were determined by 3437 and $2994 \mathrm{~cm}^{-1}$ bands (primary amine stretching) and $1638 \mathrm{~cm}^{-1}$ assigned to N-H bending [36]. The $2875 \mathrm{~cm}^{-1}$ band was attributed to C-H stretching and the 1476,790 and $719 \mathrm{~cm}^{-1}$ bands were corresponded to C-H bending [36]. The signals at 1122 and $1109 \mathrm{~cm}^{-1}$ can be explained by stretching vibrations of $\mathrm{C}-\mathrm{O}$ and $\mathrm{C}-\mathrm{N}$ groups, respectively [36]. The presence of $\mathrm{C} \equiv \mathrm{N}$ groups was proven by the band at $2105 \mathrm{~cm}^{-1}$ reflecting stretching vibrations of this group [37]. The bands in the fingerprint region in the $509-6667 \mathrm{~cm}^{-1}$ range can be related to Fe-CN linear bending and the band at $468 \mathrm{~cm}^{-1}$ to Fe-C stretching [37]. The $2010 \mathrm{~cm}^{-1}$ band indicates the presence of a $\mathrm{H}_{2} \mathrm{O}-\mathrm{Cu}-\mathrm{CN}$ moiety [37]. The results show the presence of copper cyanoferrate particles enveloped by an organic layer with hydroxyl and amine groups, probably of protein origin.

The studied gCuHCF sample contained microsized, but not nanosized, particles. These observations were confirmed by different methods: means of particle counting, dynamic light scattering and zeta-potential analysis. Particle concentration and mean size of the gCuHCF fraction, estimated by the particle counter, are $2.00 \times 10^{6} \mathrm{~mL}^{-1}$ and $3.04 \pm 1.98 \mu \mathrm{m}$, respectively.

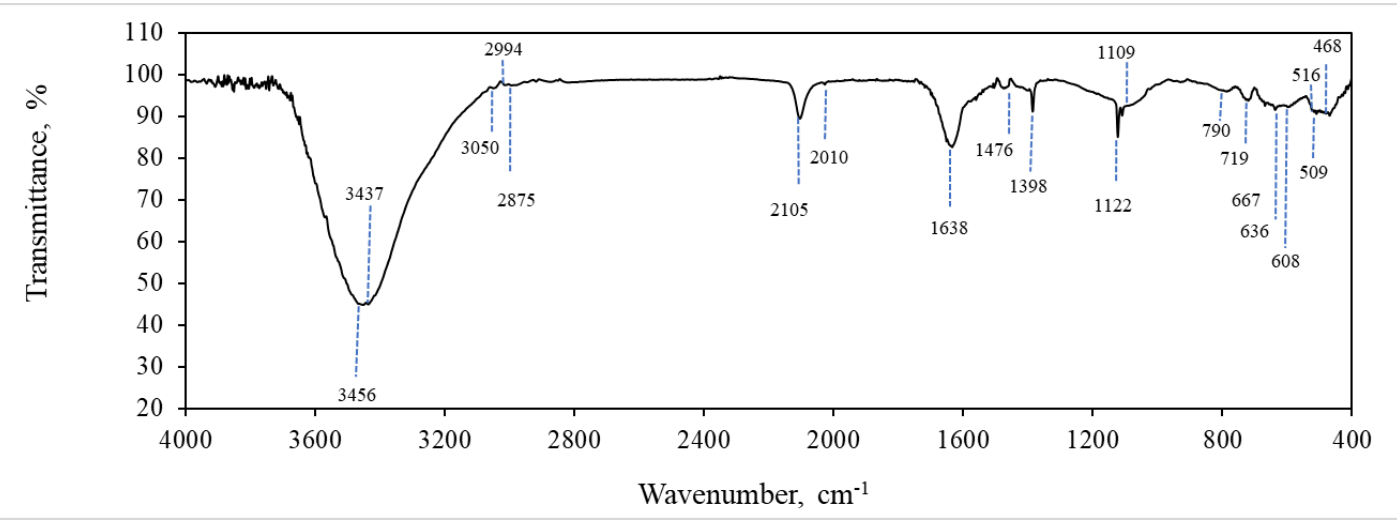

(a) 


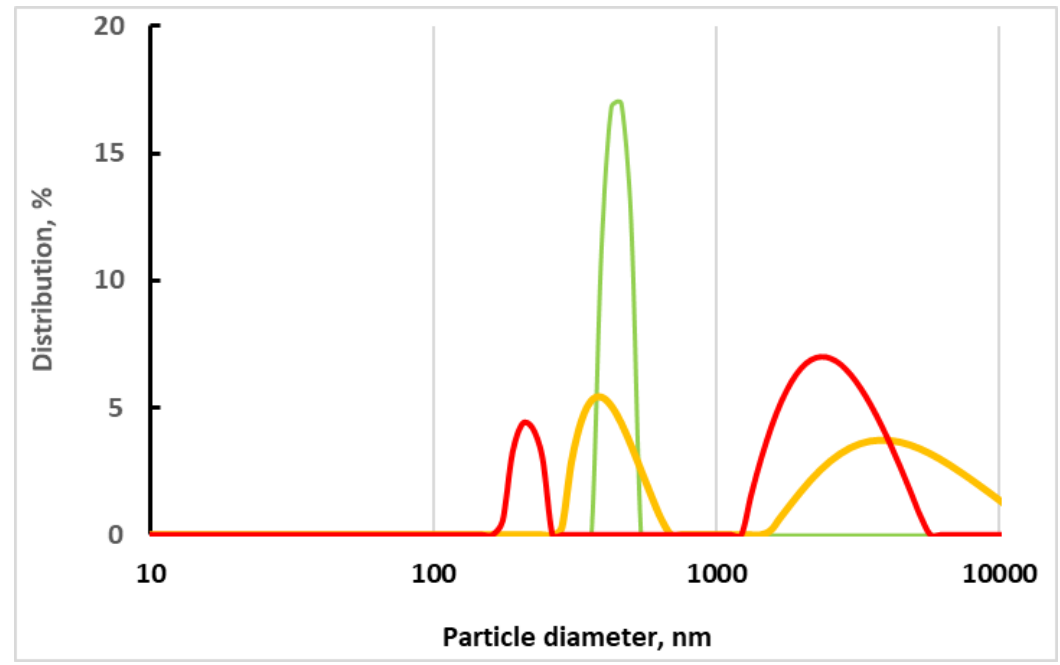

(b)

Figure 5. Characterization the gCuHCF: (a)-FTIR spectrum; (b)-DLS plots of particle hydrodynamic diameter of the sample at various concentrations: the green line represents $1.3 \times 10^{8}$ $\mathrm{mL}^{-1}$, yellow line $6.6 \times 10^{7} \mathrm{~mL}^{-1}$ and the red line $3.3 \times 10^{7} \mathrm{~mL}^{-1}$ particle concentration.

DLS demonstrated heterogeneous mean hydrodynamic diameters of the particles in a tested gCuHCF. It worth mentioning that very large differences in hydrodynamic diameters were found for various dilutions of the sample (Figure $5 \mathrm{~b}$ ). In the most concentrated sample only one size fraction was detected. There were probably larger agglomerates of particles in the concentrated suspensions, which cannot be measured by the used instrument since the upper limit of measurement was 10,000 $\mathrm{nm}$. After dilutions under gentle agitation, large aggregates disintegrated, and two fractions of particles were obtained.

In concentrated suspensions, the hydrodynamic diameter in the fraction of smaller particles was $445 \mathrm{~nm}$ (Table 2), whereas after dilution of the sample two fractions were detected (Table 2). The polydispersity index, calculated as PDI $=\left(\frac{s t . d e v}{\text { peak }}\right)^{2}$, exceeded $10 \%$ for all dilutions. This result proved that the tested sample is not monodisperse. The zeta-potential was negative and estimated as -20.9 $\mathrm{mV}$ (Table 2). This value characterizes the suspension state of $\mathrm{gCuHCF}$ as the threshold of delicate dispersion.

Table 2. DLS data and zeta-potential for the gCuHCF.

\begin{tabular}{ccccc}
\hline $\begin{array}{c}\text { Particle } \\
\begin{array}{c}\text { Concentration, } \\
\mathbf{m L}^{-1}\end{array}\end{array}$ & $\begin{array}{c}\text { Hydrodynamic } \\
\text { Diameter of the } \\
\text { Peak 1, } \mathbf{n m}\end{array}$ & $\begin{array}{c}\text { Hydrodynamic } \\
\text { Diameter of the } \\
\text { Peak } \mathbf{2}, \mathbf{n m}\end{array}$ & $\begin{array}{c}\text { Polydispersity } \\
\text { Index, } \%\end{array}$ & $\begin{array}{c}\text { Mean Zeta } \\
\text { Potential, } \\
\mathbf{~ m V ~}\end{array}$ \\
\hline $1.3 \times 10^{8}$ & 445 & $*$ ND & 33.2 & -20.9 \\
$6.6 \times 10^{7}$ & 419 & 4876 & 43.2 & ND \\
$3.3 \times 10^{7}$ & 212 & 2635 & 35.9 & ND \\
\hline
\end{tabular}

* ND-not determined.

Thus, the different analytical approaches demonstrated that the synthesized gCuHCF is a suspension of micro-particles.

gCuHCF was characterized by SEM coupled with X-ray microanalysis (SEM-XRM). SEM can afford information on the size, distribution and shape of the tested sample. Figure $6 \mathrm{a}-\mathrm{d}$ present the overall morphology of the formed flower-like particles. The XRM images of the gCuHCF film show the characteristic peaks for $\mathrm{Cu}$ and Fe (Figure 6e).

Unfortunately, we have no rule for naming the synthesized PO-like catalytically active organicinorganic material by the popular word "nanozyme". However, according to the SEM results, this material may be named "organic-inorganic micro-flowers" (hNFs). 


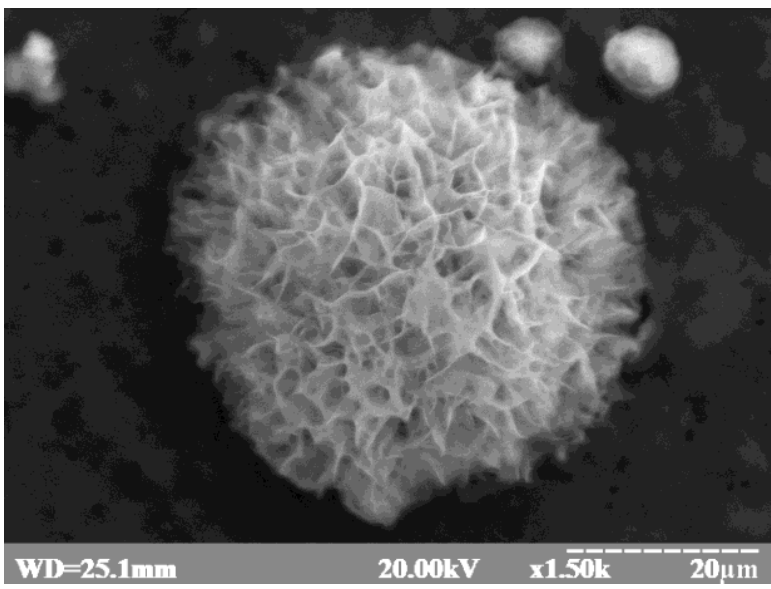

(a)

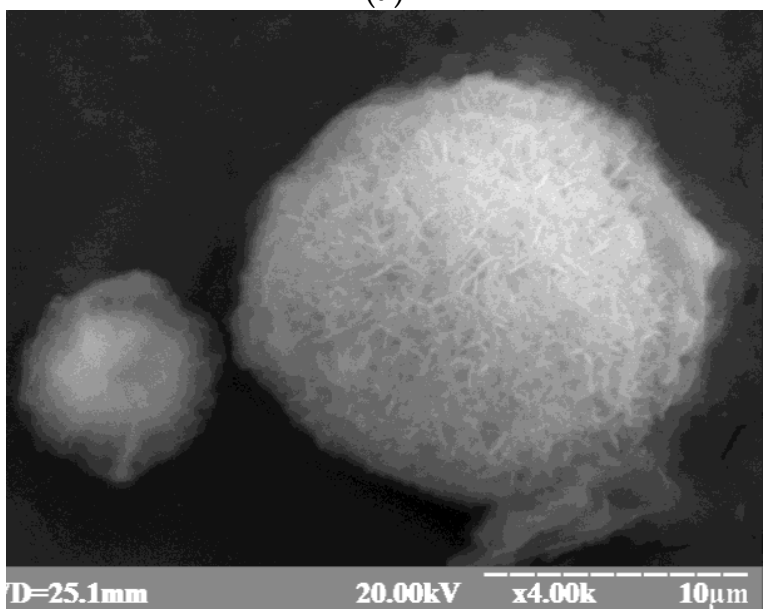

(c)

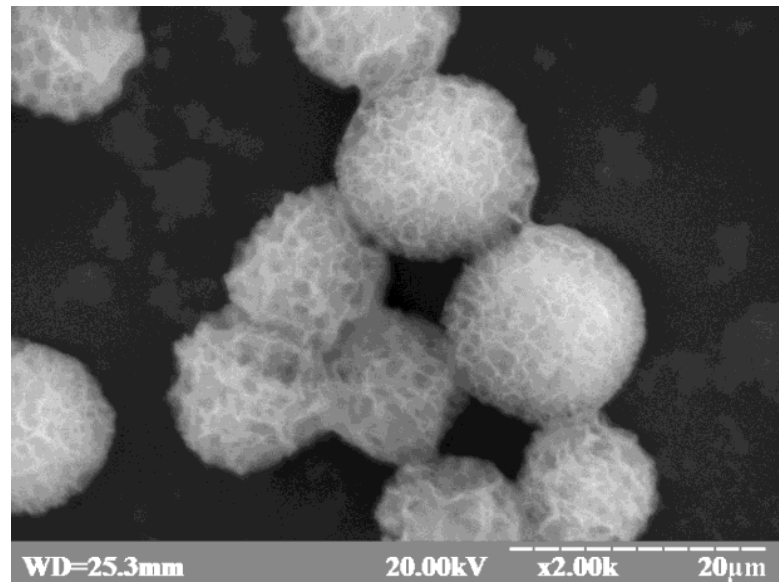

(b)

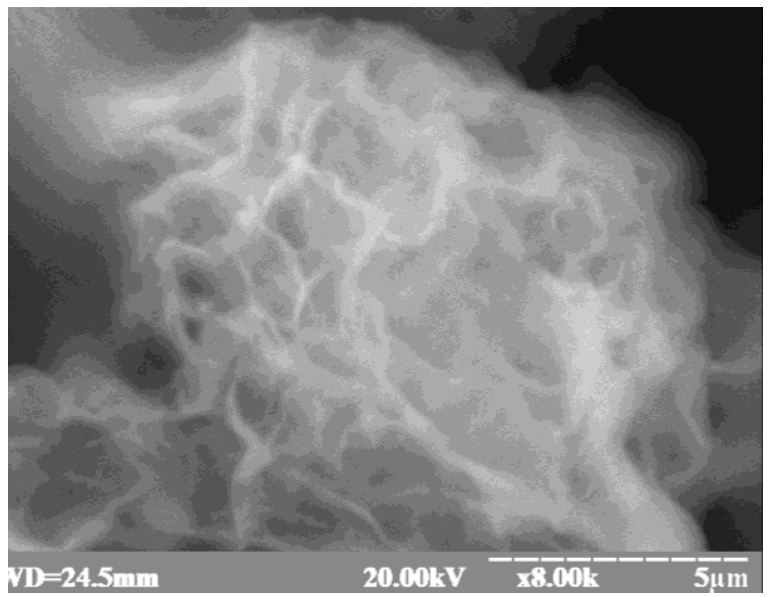

(d)

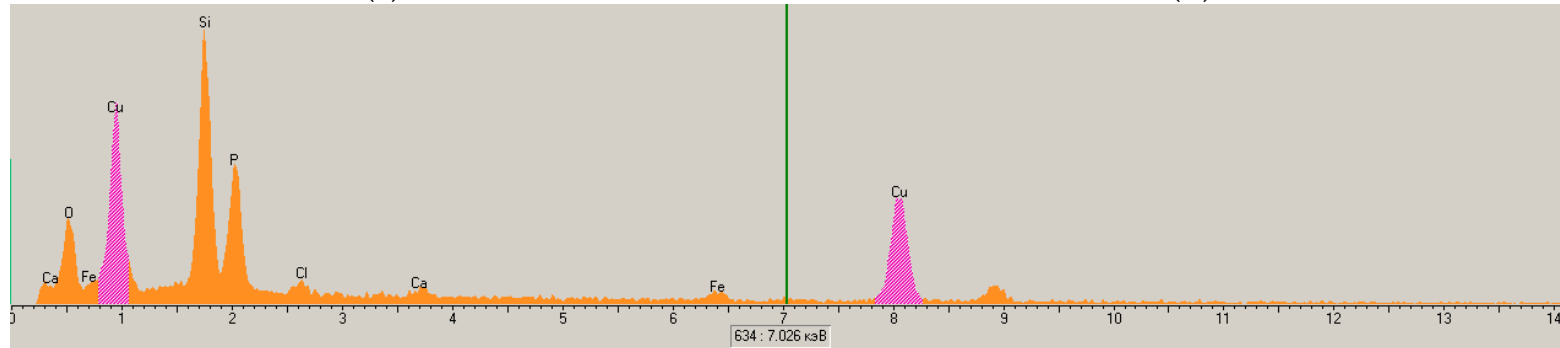

(e)

Figure 6. Characteristics of gCuHCFs: SEM images at magnifications of $\times 1500(\mathbf{a}), \times 2000(\mathbf{b}), \times 4000$ (c) and $\times 8000$ (d) and X-ray spectral characteristics of gHCFs (e).

\section{Discussion}

In the current research, we demonstrate the possibility of developing reagentless amperometric (bio)sensors with artificial peroxidases - hexacyanoferrates of transition metals, that were synthesized via green synthesis using oxidoreductase $\mathrm{Fc} b 2$. The present work is based on our previous studies on green synthesis of nanomaterials [28,33,34], obtaining and applying PO-like PtRu-containing NZs [38], as well as construction of amperometric enzymatic biosensors using the synthesized nanoparticles (NPs) of noble metals [28,38,39].

We previously studied various aspects of $\mathrm{F} c b_{2}$-mediated synthesis of $\mathrm{PB}$ and developed several highly sensitive and selective methods. One proposed method was a semi-quantitative method for visual detection of Fc $b_{2}$ activity in PAAG [33]. This method was based on an interaction between ferrocyanide (generated during the enzymatic reaction) and $\mathrm{Fe}^{3+}$, resulting in the formation of intensely colored precipitates of PB in the gel. The main advantages of this method were its high sensitivity ( $3 \mathrm{mU} \mathrm{F} \mathrm{c}_{2}$ could be detected within a reasonable time period) and stability of the formed 
dye. Another method enabled quantification of the L-lactate concentration in solution. This method was based on $\mathrm{Fc}_{2} b_{2}$-catalyzed formation of $\mathrm{PB}$, followed by its solubilization [34]. In addition, we demonstrated the possibility of using green-synthesized NPs (gNPs) of Au and Pd as enzyme carriers on the surface of graphite electrodes (GE) in amperometric laccase- and alcohol oxidase-based biosensors [28]. The extracellular metabolites of the yeast Ogataea polymorpha were used as reducing agents for obtaining gNPs from the corresponding inorganic ions. Several gNPs were synthesized, characterized and tested on the surface of GEs. The most effective Pd-based gNPs were applied for construction of biosensors for assays of phenolic compounds and alcohols. We previously described glucose-selective bi-enzyme amperometric biosensors based on GO and PO [39]. The bi-enzyme glucose-selective biosensor consisted of a combination of GO-and PO, co-immobilized with monoand bi-metallic NPs of noble metals. NPs served as the enzyme stabilizers and as electron transfer mediators. Using PO in tandem with NPs enables decreasing the working potential of the sensor to $-50 \mathrm{mV}$, which is important for preventing interfering effects of a real sample's background. All developed NPs-based biosensors exhibited higher sensitivities, wider linear ranges, lower limits of detection and higher stabilities compared to biosensors without NPs. The most effective AgNPscontaining biosensor was used for glucose analysis in wine samples.. A high correlation between glucose values estimated by the biosensor and by a commercial enzymatic kit was demonstrated [39]. We also previously reported on the development of oxidase-based bioelectrodes for food analysis using NZs as PO mimetics [38]. Bimetallic chemically synthesized PtRuNPs coupled with microbial alcohol oxidase and methylamine oxidase were chosen for constructing amperometric biosensors for primary alcohols and methylamine. Both biosensors showed high sensitivities, broad linear ranges and satisfactory storage stabilities. The practical feasibility of the constructed biosensors was demonstrated on food samples.

In the current research, the structure, size, composition, electro-catalytic properties, electromediator activity and PO-like properties of the obtained PB and its analogues, synthesized via enzyme and incorporated with it, were characterized. A more detailed study was performed on copper hexacyanoferrate (gCuHCF or gCuPBA), which was found to be the most effective PO mimetic. When immobilized on a GE, gCuHCF under special $\mathrm{pH}$ conditions and working potential gave the intrinsic amperometric response to hydrogen peroxide. We demonstrated that the synthesized gCuHCF may be successfully used as an artificial PO for sensor analysis of hydrogen peroxide in a real disinfectant sample.

A comparison between the analytical characteristics of several reported PBA-based sensors for $\mathrm{H}_{2} \mathrm{O}_{2}$ having similar sensitivities and the developed gCuHCF/GE is presented in Table 3. PO-like PBA-based sensors coupled with other nanomaterials (carbon, graphene, natural polysaccharides or synthetic polymers) demonstrated a significantly higher (from 3-5 [11,21,40-43] up to 300-fold [44]) sensitivity than the gCuPBA-based sensor. The main peculiarities of the reported sensors are high stability, sensitivity and selectivity to $\mathrm{H}_{2} \mathrm{O}_{2}$ in extra-wide linear ranges. These properties led to the successful use of the PBAs in oxidase-based biosensors [21-24,40,42,44-47,49].

An amperometric GO-based biosensor with $\mathrm{gCuHCF}$ as a $\mathrm{PO}$ mimetic was developed in the present study. Although the sensitivity of the GO/gCuHCF/GE was rather low $\left(75.6 \mathrm{~A} \cdot \mathrm{M}^{-1} \cdot \mathrm{m}^{-2}\right)$, the obtained result indicated that gCuHCF and other gPBAs can be used as PO-like composites for the construction of oxidase-based amperometric biosensors. Additional research is necessary for optimization of the biosensor construction, stabilization and exploitation methods in order to improve the sensitivity and other characteristics of the gPBA-based biosensor. First, it is necessary to screen working electrodes with different properties and to choose the optimal one. It is known that the electrode material, as well as the morphology of its surface, have significant effects on the analytical characteristics, especially on the sensitivity, of the developed biosensor. Second, it is necessary to optimize the methods for construction of the gPBA/oxidase-based electrode: the method of electrode modification with gPBA must be improved; the most effective fixing polymers/electromediators should be screened and selected; the enzyme/gHCF ratio should be determined experimentally; the modes of enzyme immobilization and stabilization on the gPBA surface needs to be studied, and so on. Third, it is necessary to improve the conditions of the biosensor's exploitation: 
the optimal buffer, $\mathrm{pH}$, working potential and other parameters should be determined. The obtained results indicate that gCuHCF and other gHCF may have a potential for use as PO-like composites for construction of amperometric biosensors with any oxidase.

Table 3. Analytical characteristics of several $\mathrm{H}_{2} \mathrm{O}_{2}$-sensitive sensors having similar sensitivities based on PBA as artificial PO This is a table.

\begin{tabular}{cccccc}
\hline Electrode & PO Mimetic & $\begin{array}{c}\text { Sensitivity, } \\
\mathbf{A ~ M}^{-1} \mathbf{m}^{-2}\end{array}$ & $\begin{array}{c}\text { LOD, } \\
\boldsymbol{\mu M}\end{array}$ & $\begin{array}{c}\text { Linear Range, } \\
\boldsymbol{\mu M}\end{array}$ & Ref. \\
\hline${ }^{1}$ GCE & PB & 2000 & & & {$[48]$} \\
GCE & Ni-Fe PBA-4HNCs & 361 & & $0.1-20000$ & {$[49]$} \\
GCE & MnPBA & 1472 & & $3-8610$ & {$[50]$} \\
GCE & Ni-PB & 3500 & & $0.1-1000$ & {$[51]$} \\
Graphite paste & Ni-FePBA & 1130 & 2 & $2-1000$ & {$[52]$} \\
& Cu-FePBA & 2030 & 0.2 & $0.5-1000$ & \\
${ }^{2}$ DBD & PB & 2100 & 0.5 & $0.5-1000$ & {$[53]$} \\
DBD & Ni-FePBA & 1500 & & & Current paper \\
\hline${ }^{3}$ GE & gCuPBA & 1620 & 2 & $10-800$ & .
\end{tabular}

${ }^{1} \mathrm{GCE}-$ glassy carbon electrode; ${ }^{2} \mathrm{DBD}-$ Diamond Boron-doped; ${ }^{3} \mathrm{GE}-$ graphite electrode;

${ }^{4} \mathrm{HNCs}$ - hollow nanocubes.

SEM imaging shows that gCuHCF has a flower-like structure and can be related to a class of flower-like hybrid materials (hNFs) that self-assemble from metal ions and organic components (for example enzymes, DNA and amino acids) into flower-like micro/nano superstructures [54,55]. hNFs are widely used for the development of stable, robust, reusable, efficient and cost-effective systems for immobilization of biomolecules [55-57]. Some hNFs were shown to exhibit an intrinsic PO-like activity. Due to their remarkable performances, namely the simplicity of their synthesis, their high surface area, excellent thermal, storage and $\mathrm{pH}$ stability and catalytic activity, hNFs may become promising platforms for biosensor construction. gHCFs of transition metals, including hNFs, synthesized using different enzymes, may be effectively applied for construction of amperometric (bio)sensors.

Author Contributions: Conceptualization: G.Z.G. and M.N.; methodology: O.M.D., G.Z.G. and Y.G.; investigation: O.M.D., R.Y.S., and Y.G.; resources: M.V.G.; data curation: G.Z.G. and M.N.; writing - original draft preparation: G.Z.G., and O.M.D.; writing - review and editing: G.Z.G. and M.N.; supervision: M.V.G.; project administration: G.Z.G.; funding acquisition: M.V.G. and M.N. All authors have read and agreed to the published version of the manuscript.

Funding: This work was partially funded by NAS of Ukraine (The program "Smart sensor devices of a new generation based on modern materials and technologies", project 0118U006260), by the Ministry of Education and Science of Ukraine (Ukrainian- Lithuanian R\&D, project 0120U103398), by NRFU (project ID: 2020.02/0100 "Development of new nanozymes as catalytic elements for enzymatic kits and chemo/biosensors") and by the Research Authority of the Ariel University, Israel.

Acknowledgments: We acknowledge Mariya F. Ivash (Institute of Cell Biology) for technical support and Mariya V. Pidluzna (M.Sc. student of Ivan Franko National University of Lviv, Ukraine) for experimental assistance.

Conflicts of Interest: The authors declare no conflict of interest. 


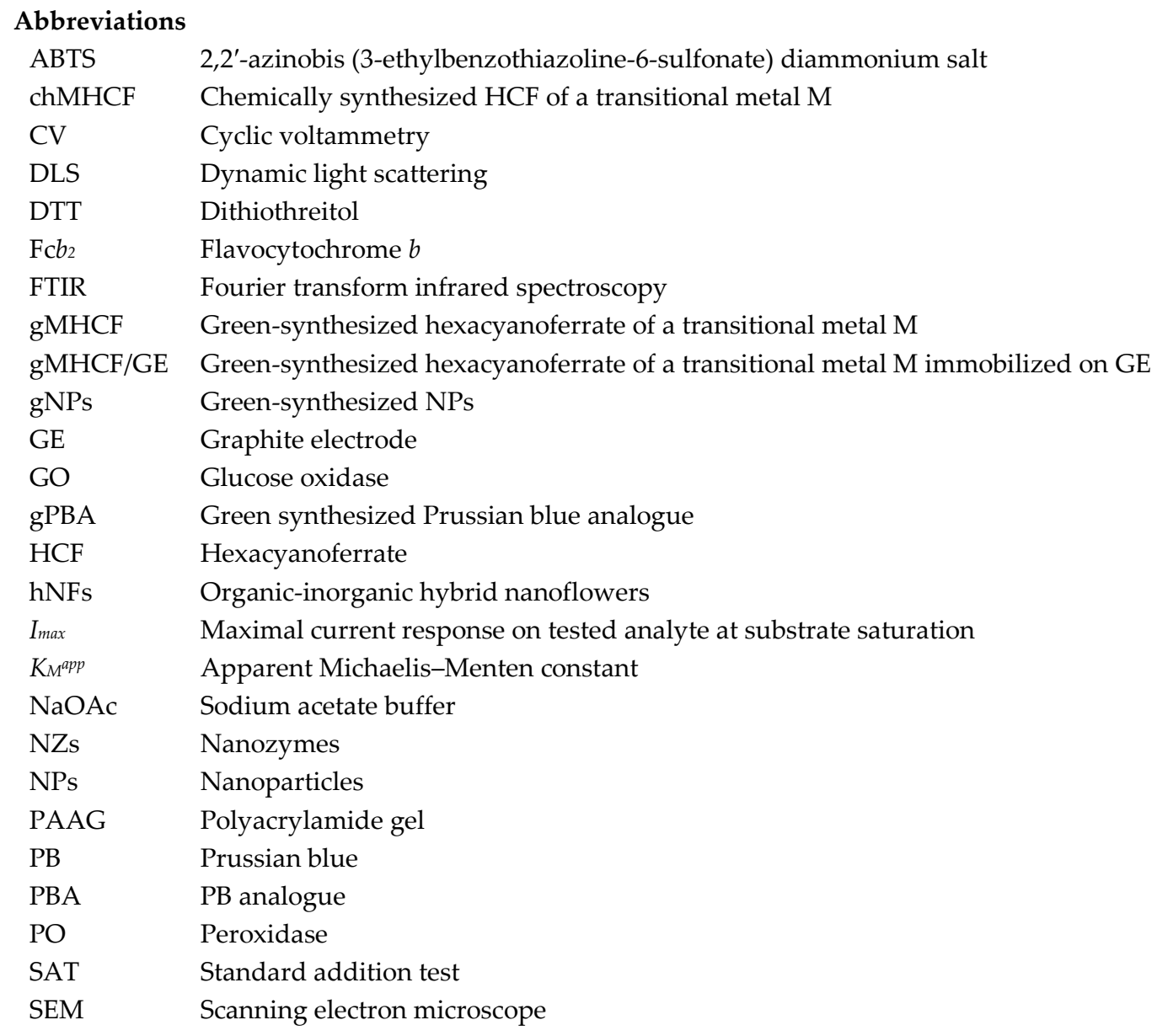

\section{References}

1. Wu, J.; Wang, X.; Wang, Q.; Lou, Z.; Li, S.; Zhu, Y.; Qin, L.; Wei, H. Nanomaterials with enzyme-like characteristics (nanozymes): Next-generation artificial enzymes (II). Chem. Soc. Rev. 2019, 48, 1004-1076, doi:10.1039/c8cs00457a.

2. Huang, Y.; Ren, J.; Qu, X. Nanozymes: Classification, Catalytic Mechanisms, Activity Regulation, and Applications. Chem. Rev. 2019, 119, 4357-4412, doi:10.1021/acs.chemrev.8b00672.

3. Stasyuk, N.; Smutok, O.; Demkiv, O.; Prokopiv, T.; Gayda, G.; Nisnevitch, M.; Gonchar, M. Synthesis, Catalytic Properties and Application in Biosensorics of Nanozymes and Electronanocatalysts: A Review. Sensors 2020, 20, 4509-4550, doi:10.3390/s20164509.

4. Liang, M.; Yan, X. Nanozymes: From New Concepts, Mechanisms, and Standards to Applications. Acc. Chem. Res. 2019, 5, 2190-2200, doi:10.1021/acs.accounts.9b00140.

5. Wang, P.; Wang, T.; Hong, J.; Yan, X.; Liang, M. Nanozymes: A New Disease Imaging Strategy. Front. Bioeng. Biotechnol. 2020, 8, 1-10, doi:10.3389/fbioe.2020.00015.

6. Nayl, A.A.; Abd-Elhamid, A.I.; El-Moghazy, A.Y.; Hussin, M.; Abu-Saied, M.A.; El-Shanshory, A.A.; Soliman, H.M.A. The nanomaterials and recent progress in biosensing systems: A review. Trends Environ. Anal. Chem. 2020, 26, e00087, doi:10.1016/j.teac.2020.e00087.

7. Mahmudunnabi, R.; Farhana, F.Z.; Kashaninejad, N.; Firoz, S.H.; Shim, Y.B.; Shiddiky, M.J.A. Nanozymebased electrochemical biosensors for disease biomarker detection. Analyst 2020, 145, 4398-4420, doi:10.1039/d0an00558d.

8. Guari, Y.; Larionova ${ }_{\llcorner}$J. (Eds). Prussian Blue-Type Nanoparticles and Nanocomposites: Synthesis, Devices, and Applications: Synthesis, Devices, and Applications; Pan Stanford Publishing Pte Ltd: Singapore, 2019; 314p. ISBN 978-981-4800-05-1.

9. Ivanov, V.D. Four decades of electrochemical investigation of Prussian blue. Ionics 2020, 26, 531-547, doi:10.1007/s11581-019-03292-y.

10. Ojwang, D.O. Prussian Blue Analogue Copper Hexacyanoferrate: Synthesis, Structure Characterization and Its Applications as Battery Electrode and $\mathrm{CO}_{2}$ Adsorbent. Ph.D. Thesis, Stockholm University, 
Stockholm, Sweden, 13 October 2017. Available online: http://www.divaportal.org/smash/record.jsf?pid=diva2\%3A1136799\&dswid=8693 (accessed on 10 July 2020).

11. Matos-Peralta, Y.; Antuch, M. Review-Prussian Blue and its analogs as appealing materials for electrochemical sensing and biosensing. J. Electrochem. Soc. 2020, 167, 037510, doi:10.1149/2.0102003JES.

12. Rauwel, P.; Rauwel, E. Towards the Extraction of Radioactive Cesium-137 from Water via Graphene/CNT and Nanostructured Prussian Blue Hybrid Nanocomposites: A Review. Nanomaterials 2019, 9, 682-703, doi:10.3390/nano9050682.

13. Jia, Q.; Li, Z.; Guo, C.; Huang, X.; Kang, M.; Song, Y.; He, L.; Zhou, N.; Wang, M.; Zhang, Z.; et al. PEGMAmodified bimetallic NiCo Prussian blue analogue doped with $\mathrm{Tb}(\mathrm{III})$ ions: Efficiently pH-responsive and controlled release system for anticancer drug. Chem. Eng. 2020, 389, 124468, doi:10.1016/j.cej.2020.124468.

14. Wang, X.; Li, H.; Li, F.; Han, X.; Chen, G. Prussian blue-coated lanthanide-doped core/shell/shell nanocrystals for NIR-II image-guided photothermal therapy. Nanoscale 2019, 11, 22079-22088, doi:10.1039/C9NR07973D.

15. He, L.; Li, Z.; Guo, C.; Hu, B.; Wang, M.; Zhang, Z.; Du, M. Bifunctional bioplatform based on NiCo Prussian blue analogue: Label-free impedimetric aptasensor for the early detection of carcino-embryonic antigen and living cancer cells. Sens. Actuators B Chem. 2019, 298, 126852, doi:10.1016/j.snb.2019.126852.

16. Komkova, M.A.; Karyakina, E.E.; Karyakin, A.A. Catalytically Synthesized Prussian Blue Nanoparticles Defeating Natural Enzyme Peroxidase. J. Am.Chem. Soc. 2018, 140, 11302-11307, doi:10.1021/jacs.8b05223.

17. Tian, M.; Xie, W.; Zhang, T.; Liu, Y.; Lu, Z.; Li, C.M.; Liu, Y. Sensitive lateral flow immunochromatographic strip with Prussian blue nanoparticles mediated signal generation and cascade amplification. Sens. Actuators B Chem. 2020, 309, 127728, doi:10.1016/j.snb.2020.127728.

18. Chen, W.; Gao, G.; Jin, Y.; Deng, C.A facile biosensor for $\mathrm{A} \beta 40 \mathrm{O}$ based on fluorescence quenching of prussian blue nanoparticles. Talanta 2020, 216, 120390, doi:10.1016/j.talanta.2020.120930.

19. Nai ${ }_{\lrcorner} . ;$Lou, X.W.D. Hollow Structures Based on Prussian Blue and Its Analogs for Electrochemical Energy Storage and Conversion. Adv. Mater. 2019, 31, 1706825, doi:10.1002/adma.201706825.

20. Itaya, K.; Shoji, N.; Uchida, I. (Catalysis of the reduction of molecular oxygen to water at Prussian blue modified electrodes. J. Am. Chem. Soc. 1984, 106, 3423-3429, doi:10.1021/ja00324a007.

21. Karyakin, A.A.; Karyakina, E.E.; Gorton, L. Amperometric Biosensor for Glutamate Using Prussian BlueBased "Artificial Peroxidase" as a Transducer for Hydrogen Peroxide. Anal. Chem. 2000, 72, 1720-1723, doi:10.1021/ac990801o.

22. Komkova, M.A.; Karyakin, A.A.; Andreev, E.A. Power output of Prussian Blue based (bio)sensors as a function of analyte concentration: Towards wake-up signaling systems. J. Electroanal. Chem. 2019, 847, 113263, doi:10.1016/j.jelechem.2019.113263.

23. Komkova, M.A.; Andreev, E.A.; Ibragimova, O.A.; Karyakin, A.A. Prussian Blue based flow-through (bio)sensors in power generation mode: New horizons for electrochemical analyzers. Sens. Actuators $B$ Chem. 2019, 292, 284-288, doi:10.1016/j.snb.2019.04.134.

24. Karyakin, A.A. Advances of Prussian blue and its analogues in (bio)sensors. Curr. Opin. Electrochem. 2017, 5, 92-98, doi:10.1016/j.coelec.2017.07.006.

25. Jassal, V.; Shanker, U.; Kaith, B.S. Aegle marmelos mediated green synthesis of different nanostructured metal hexacyanoferrates: Activity against photodegradation of harmful organic dyes. Hindawi. Pub. Corp. 2016, 2016, 2715026, doi:10.1155/2016/2715026.

26. Lee, I.; Kang, S.M.; Jang, S.C.; Lee, G.W.; Shim, H.E.; Rethinasabapathy „M.; Roh С C.; Huh, Y.S. One-pot gamma ray-induced green synthesis of a Prussian blue-laden polyvinylpyrrolidone/reduced graphene oxide aerogel for the removal of hazardous pollutants. J. Mater. Chem. A 2019, 7, 1737-1748, doi:10.1039/C8TA10250C.

27. Gour, A.; Jain, N.K. Advances in green synthesis of nanoparticles. Artif. Cells Nanomed. Biotechnol. 2019, 47, 844-851, doi:10.1080/21691401.2019.1577878.

28. Gayda, G.Z.; Demkiv, O.M.; Stasyuk, N.Y.; Serkiz, R.Y.; Lootsik, M.D.; Errachid, A.; Gonchar, M.V.; Nisnevitch, M. Metallic nanoparticles obtained via "green" synthesis as a platform for biosensor construction. Appl. Sci. 2019, 9, 720-736, doi:10.3390/app9040720.

29. Chinnadayyala, S.R.; Santhosh, M.; Singh, N.K.; Goswami, P. Alcohol oxidase protein mediated in-situ synthesized and stabilized gold nanoparticles for developing amperometric alcohol biosensor. Biosens. Bioelectron. 2015, 69, 155-161, doi:10.1016/j.bios.2015.02.015.

30. Vetchinkina, E.P.; Loshchinina, E.A.; Vodolazov, I.R.; Kursky, V.F.; Dykman, L.A.; Nikitina, V.E. Biosynthesis of nanoparticles of metals and metalloids by basidiomycetes. Preparation of gold 
nanoparticles by using purified fungal phenol oxidases. Appl. Microbiol. Biotechnol. 2017, 101, 1047-1062, doi:10.1007/s00253-016-7893-x.

31. Kharissova, O.V.; Kharisov, B.I.; Oliva González, C.M.; Méndez, Y.P.; López, I. Greener synthesis of chemical compounds and materials. R. Soc. Open Sci. 2019, 6, 191378, doi:10.1098/rsos.191378.

32. Jassal, V.; Shanker, U.; Kaith, B.S.; Shankar, S. Green synthesis of potassium zinc hexacyanoferrate nanocubes and their potential application in photocatalytic degradation of organic dyes. RSC Adv. 2015, 5, 26141-26149, doi:10.1039/C5RA03266K.

33. Gaida, G.Z.; Stel'mashchuk, S.Y.; Smutok, O.V.; Gonchar, M.V. A new method of visualization of the enzymatic activity of flavocytochrome $b_{2}$ in electrophoretograms. Appl. Biochem. Microbiol. 2003, 39, 221223, doi:10.1023/A:1022558501487.

34. Gonchar, M.; Smutok, O.; Os'mak, H. Flavocytochrome $b_{2}$-Based Enzymatic Composition, Method and Kit for L-Lactate. Patent Application PCT/US2008/069637, Publ.WO/2009/009656. 2009. Available online: http://www.wipo.int/pctdb/en/wo.jsp?WO=2009009656 (accessed on 14 August 2020).

35. Synenka, M.M.; Stasyuk, N.Ye.; Semashko, T.V.; Gayda, G.Z.; Mikhailova, R.V.; Gonchar, M.V. Immobilization of oxidoreductases at/on gold and silver nanoparticles. Stud. Biol. 2014, 8, 5-16, doi:10.30970/sbi.0803.365.

36. IR Spectrum Table \& Chart. Available online: https://www.sigmaaldrich.com/technicaldocuments/articles/biology/ir-spectrum-table.html (accessed on 7 September 2020).

37. Mink, J.; Stirling, A.; Ojwang, D.O.; Svensson, G.; Mihály, J.; Németh, C.; Drees, M.; Hajba, L. Vibrational properties and bonding analysis of copper hexacyanoferrate complexes in solid state. Appl. Spectros. Rev. 2018, 54, 369-424, doi:10.1080/05704928.2018.1459659.

38. Stasyuk, N.; Gayda, G.; Zakalskiy, A.; Zakalska, O.; Serkiz, R.; Gonchar, M. Amperometric biosensors based on oxidases and PtRu nanoparticles as artificial peroxidase. Food Chem. 2019, 285, 213-220, doi:10.1016/j.foodchem.2019.01.117.

39. Gayda, G.; Klepach, H.; Semashko, T.; Gonchar, M. Nanoparticles of noble metals for enzymatic sensors: An amperometric glucose biosensor for wine analysis. Sens. Lett. 2017, 15, 647-654, doi:10.1166/sl.2017.3862.

40. Karyakin, A.A.; Gitelmacher, O.V.; Karyakina, E.E. Prussian Blue-Based First-Generation Biosensor. A Sensitive Amperometric Electrode for Glucose. Anal. Chem. 1995, 67, 14, 2419-2423, doi: 10.1021/ac00110a016.

41. Keihan, A.H.; Karimi, R.R.; Sajjadi, S. Wide dynamic range and ultrasensitive detection of hydrogen peroxide based on beneficial role of gold nanoparticles on the electrochemical properties of prussian blue. J. Electroanal. Chem. 2020, 862, 114001, doi:10.1016/j.jelechem.2020.114001.

42. Vokhmyanina, D.V.; Andreeva, K.D.; Komkova, M.A.; Karyakina, E.E.; Karyakin, A.A. Artificial peroxidase" nanozyme - Enzyme based lactate biosensor. Talanta 2020, 208, 120393, doi:10.1016/j.talanta.2019.120393.

43. Huang, J.; Lu, S.; Fang, X.; Yang, Z.; Liu, X.; Li, S.; Feng, X. Optimized deposition time boosts the performance of Prussian blue modified nanoporous gold electrodes for hydrogen peroxide monitoring. Nanotechnology 2020, 31, 045501, doi:10.1088/1361-6528/ab4d01.

44. Clausmeyer, J.; Actis, P.; Córdoba, A.L.; Korchev, Y.; Schuhmann, W. Nanosensors for the detection of hydrogen peroxide. Electrochem. Commun. 2014, 40, 28-30, doi:10.1016/j.elecom.2013.12.015.

45. Valiūnienè, A.; Virbickas, P.; Rekertaitè, A.; Ramanavičius, A. Amperometric Glucose Biosensor Based on Titanium Electrode Modified with Prussian Blue Layer and Immobilized Glucose Oxidase. J. Electrochem. Soc. 2017, 164, B781-B784, doi:10.1149/2.0151802jes.

46. Virbickas, P.; Valiūnienè, A.; Kavaliauskaitė, G.; Ramanavicius, A. Prussian White-Based Optical Glucose Biosensor. J. Electrochem. Soc. 2019, 166, B927-B932, doi:10.1149/2.0511912jes.

47. Chen, J.; Yu, Q.; Fu, W.; Chen, X.; Quan Zhang, Q.; Dong, S.; Chen, H.; Zhang, S. A Highly Sensitive Amperometric Glutamate Oxidase Microbiosensor Based on a Reduced Graphene Oxide/Prussian Blue Nanocube/Gold Nanoparticle Composite Film-Modified Pt Electrode. Sensors 2020, 20, 2924-2938, doi:10.3390/s20102924.

48. Puganova, E.A.; Karyakin, A.A. New materials based on nanostructured Prussian blue for development of hydrogen peroxide sensors. Sens. Actuators B 2005, 109, 167-170, doi:10.1016/j.snb.2005.03.094. 
49. Niu, Q.; Bao, C.; Cao, X.; Liu, C.; Wang, H.; Lu, W. Ni-Fe PBA hollow nanocubes as efficient electrode materials for highly sensitive detection of guanine and hydrogen peroxide in human whole saliva. Biosens. Bioelectron. 2019, 141, 111445, doi:10.1016/j.bios.2019.111445.

50. Pang, H.; Zhang, Y.; Cheng, T.; Lai, W.Y.; Huang, W. Uniform manganese hexacyanoferrate hydrate nanocubes featuring superior performance for low-cost supercapacitors and nonenzymatic electrochemical sensors. Nanoscale 2015, 7, 16012-16019, doi:10.1039/c5nr04322k.

51. Sitnikova, N.A.; Borisova, A.V.; Komkova, M.A.; Karyakin, A.A. Superstable advanced hydrogen peroxide transducer based on transition metal hexacyanoferrates. Anal. Chem. 2011, 83, 2359-2363, doi:10.1021/ac1033352.

52. Pandey, P.C.; Panday, D.; Pandey, A.K. Polyethylenimine mediated synthesis of copper-iron and nickeliron hexacyanoferrate nanoparticles and their electroanalytical applications. J. Electroanal. Chem. 2016, 780, 90-102, doi:10.1016/j.jelechem.2016.08.026.

53. Komkova, M.A.; Pasquarelli, A.; Andreev, E.A.; Galushin, A.A.; Karyakin, A.A. Prussian Blue modified boron-doped diamond interfaces for advanced $\mathrm{H}_{2} \mathrm{O}_{2}$ electrochemical sensors. Electrochim. Acta 2020, 339, 135924, doi:10.1016/j.electacta.2020.1359244.

54. Ge, J.; Lei, J.; Zare, R.N. Protein-inorganic hybrid nanoflowers. Nat. Nanotechnol. 2012, 7, 428-432, doi:10.1038/nnano.2012.80.

55. Zhu, J.; Wen, M.; Wen, W.; Du, D.; Zhang, X.; Wang, S.; Lin, Y. Recent progress in biosensors based on organic-inorganic hybrid nanoflowers. Biosens. Bioelectron. 2018, 120, 175-187, doi:10.1016/j.bios.2018.08.058.

56. Cui, J.; Jia, S. Organic-inorganic hybrid nanoflowers: A novel host platform for immobilizing biomolecules. Review. Coord. Chem. Rev. 2017, 352, 249-263, doi:10.1016/j.ccr.2017.09.008.

57. Dong, W.; Chen, G.; Hu, X.; Zhang, X.; Shi, W.; Fu, Z. Molybdenum disulfides nanoflowers anchoring ironbased metal organic framework: A synergetic catalyst with superior peroxidase-mimicking activity for biosensing. Sens. Actuators. B. Chem. 2020, 305, 127530, doi:10.1016/j.snb.2019.127530.

Publisher's Note: MDPI stays neutral with regard to jurisdictional claims in published maps and institutional affiliations.

(C) 2020 by the authors. Submitted for possible open access publication under the terms and conditions of the Creative Commons Attribution (CC BY) license (http://creativecommons.org/licenses/by/4.0/). 